\title{
Visual search and memory under degraded and masked presentation'
}

\author{
LIONEL STANDING; and RALPII NORMAN IIABER, \\ University of Rochester, Rochester, N. Y. 14627
}

Each of four Ss were shown brief flashes of four lellers. They were required on some trials to name as many as they could (memory); on others they were told one letter before the flash and asked if the letter had been among the four in the stimulis (search). Both tasks were tested tunder wo eonditions: degraded. in which the duration of the stimulus was raried from 10 to 300 msec; and masked, in which the duration was held constant but visual noise followed after a 0 to 140 mse' delay. Masking and degrading affected the relative performance in the two tasks identically, although after correction for chance, search accuracy slightly exceeded memory accuracy. To search or to recall brief visual displays apparently involves similar information-processing mechanisms-most likely a serial item-by-item order.

Visual search has been under recent investigation (e.g., Stemberg, 1967; Neisser, 1967) but it has not yet been amenable to an unambiguous model. Sternberg argues if a $S$ is searching memory for an item, that search is serial (each item in memory is examined in turn) and exhaustive (a search is not terminated until all items are compared). Neisser argues, however, that if the $S$ is searching a list for one or more items that he has in memory, that search can be parallel (all of the items in memory can be tested at one time).

Memorizing visual presentation of items has been viewed as a serial information processing task by Sperling $(1963,1967)$, Haber (1969), and Neisser (1967), among others. The stimulus exposure registers the items in a rapidly decaying short-term visual storage from which the $S$ must process each item serially by encoding it and transferring it to a short-term memory where it can be rehearsed or retrieved for support.

Degrading the stimulus presentation (e.g., reducing its duration, luminance, visual angle or contrast) should reduce the adequacy of registration but not interfere with the processing of the information so registered. However, following the stimulus with visual noise is thought to affect not the registration but the time which the $S$ has to process each of the items serially (e.g., see Liss, 1967, 1968; Haber, 1968, 1969; Haber \& Nathanson, 1968, Aaronson, 1967).

Given these assumptions about searching; memorizing. degrading, and masking, a comparison of performance of a visual search and a visual memory task under both degraded and masked presentations should permit an analysis of the information processing characteristics of each task. For example, if degrading and masking affects both search and memory in the same way, then both tasks are probably being performed in the same way-most likely serially. However. if they differ, and especially if visual noise disrupts memory more than search, then search is likely to be a parallel process.

The following study explores these comparisons experimentally.

Subjects

\section{METHOD}

Four naive students at the University of Rochester served as Ss. Each had normal or corrected-to-normal vision, and each had at least $4 \mathrm{~h}$ of practice prior to the experiment.

Apparatus

A three channel Tachistoscope (Scientific Prototype Model GA) was used. All fields were set at $15 \mathrm{~mL}$. The $S$ viewed the stimulus monocularly. using his right eye through a $4 \mathrm{~mm}$ artificial pupil.
Stinuli

The stimuli were four-letter arrays with the letters arranged in a square. Upper-cuse letters were used, typed in black on a white background. Each array was randomly selected from all possible letters except "I" and "Q." Letter size was $5 \mathrm{~mm}$ high x $3 \mathrm{~mm}$ or less wide, with a viewing distance at $110 \mathrm{~cm}$. The array size was $2.1 \mathrm{~cm} \times 2.1 \mathrm{~cm}$. The vertical visual angle was $16 \mathrm{~min}$ for each letter. A noise field, copied from Sperling (1963), was used in the second channel for the visual noise condition, and was always exposed for $500 \mathrm{msec}$.

Procedure

Each $\mathrm{S}$ was given 10 sessions, alternating between masked or degraded presentation. Within each session, eight different stimulus durations (or eight different interstimulus intervals) were used in a random order. For each stimulus value, 10 memory trials and 10 search trials were performed. The memory and the search trials were blocked and counterbalanced for order. In the memory task the $S$ was required to guess the identity of the four letters on each flash. He was permitted to name them in any order and did not need to identify their locations. In the search task the $E$ read a different target letter before each trial. The $S$ was required to search the array for that letter and to indicate "yes" or "no" according to whether or not he thought the letter was present. The $S$ was not required to identify its position in the urray. The S was told (truthfully) that the letter was present on $50 \%$ of the trials. Feedback was given on all trials as to what the correct answer or answers were. In the degraded conditions, the stimulus durations used were 10. 15, 20,30, 50, 100. 200. and $300 \mathrm{msec}$, respectively. In the masked conditions the stimulus was exposed for $50 \mathrm{msec}$ at $0,20,50,80$, and 140 msec ISI. In addition, three other 0 ISI conditions were run, in which the stimulus was exposed for 30,200 , and at 300 msec.

\section{RESULTS}

Before the memory data can be compared to the search data. both sets need to be corrected for their relative levels of chance performance. The memory data are corrected using the formula $n^{\prime}=1 / 24\left(n^{2}+16 n+16\right)$ where $n^{\prime}=$ number of jtems
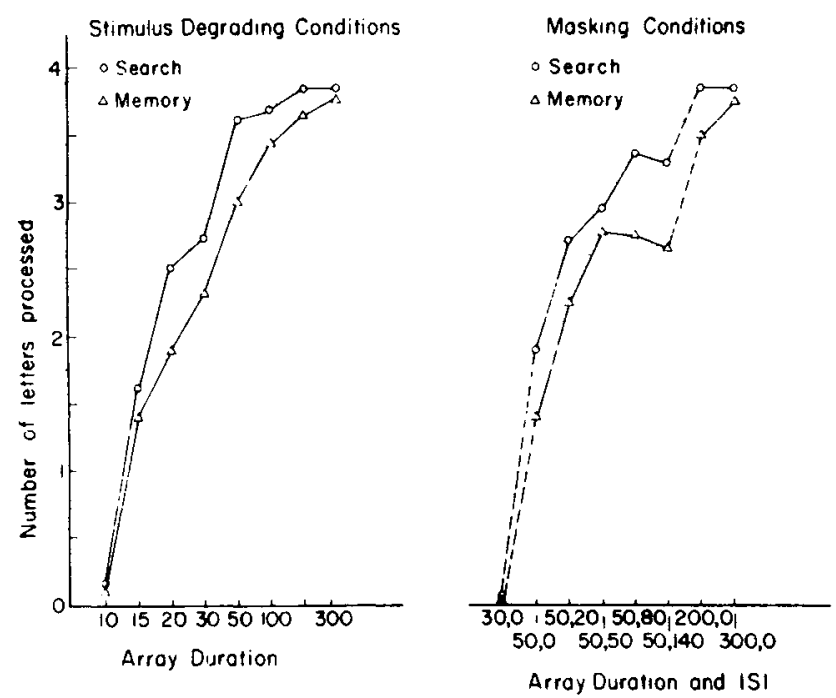

Fig. 1. Corrected performance on a search and a memory task for two conditions of presentation-masked and degraded. Data are summed over four Ss. Each data point represents 200 observations. 


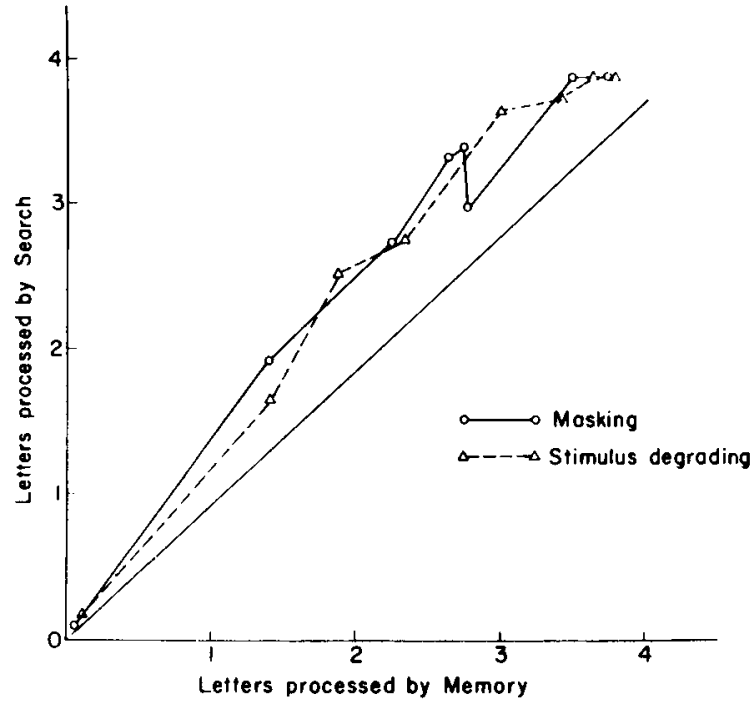

Fig. 2. Mean corrected number of letters processed per trial in search and memory tasks under stimulus degrading and under masking conditions.

scored correct per trial, and $\mathrm{n}=$ number of items correctly seen by $\mathrm{S}$.

The search data are corrected according to the formula:

$$
p^{\prime}=\frac{3}{16} n+\frac{P g n^{2}}{32}-\frac{P g n}{4}=\frac{n^{2}}{64}+.5
$$

Where $p^{\prime}=$ uncorrected probability of correct response, $n=$ number of items correctly seen by $\mathrm{S}$, and $\mathrm{Pg}=$ probability of $\mathrm{S}$ guessing "yes" when he has not seen the target item.

These formulae assume that $\mathrm{S}$ guesses randomly when he laas not seen an item (or located the target item). They also assume that for each level of task difficulty in the search task $\mathrm{Pg}$ may be estimated by the false-alarm rate found at that level.

Figure 1 presents the data to compare the effects of search and memory. While an analysis of variance is clearly inappropriate due to wide heterogeneity of variance, sign tests for each $S$ separately indicate that the corrected search scores are above the comparable corrected memory scores $(p<.01)$. Prior to correction, the search scores were substantially above. Given the assumption of the correction formulae, more items are effectively processed per trial in a search than in a memory task. However, the differences are not great.

Figure 2 replots the data to compare the effects of degraded and masked presentations. This is done by graphing search against memory performance. As can be seen, the two parameters are virtually identical, over the entire range of performance. (The slight superiority of search is again shown by the placement of both curves above the diagonal.)

\section{DISCUSSION}

\section{Search vs Memory}

The uncorrected search data are considerably above the memory data and even after the correction for guessing, the search data performance is still slightly better. If the assumptions of the correction formulae are violated, with $S$ guessing at an above-chance level on trials in which iterns have not been fully processed, this behavior still corresponds to a superiority for the search task. Thus, it seems to be somewhat easier to search a percept or its representation for a previously labeled item, than it is to maintain up to four items in memory and retrieve them for report. This is not particularly surprising on either intuitive or theoretical grounds. Further, this is true whether the items are degraded or masked.

Degraded vs Masked Presentation

In the degraded condition, as the stimulus exposures increased, performance on both memory and search increases monotonically and nearly linearly until it reaches an asymptotic level around a $200 \mathrm{msec}$ presentation. In the masked condition, four different exposure durations were used $(0,50,200,300 \mathrm{msec})$ but only with a $50 \mathrm{msec}$ were ISIs other than $0 \mathrm{msec}$ used. For that condition, performance is asymptotic after the mask is delayed by $50 \mathrm{msec}$. This is true for both search and memory.

It is clear that the mask interferes with performance unless it is delayed, or unless the exposure is so long that no further time is needed. Thus, the 200 or $300 \mathrm{msec}$ exposures, even with an immediate mask, are equivalent to flashes without masking, but a $30 \mathrm{msec}$ flash permits higher performance (60 to $70 \%$ ) if there is no mask, then it is followed by visual noise (20 to $30 \%$ ). Since this study was not designed to study the processes by which masking has its effects, an insufficient number of data points were chosen with which to carry this analysis further.

An unexpected finding concerns a close similarity of search to memory under both degraded and masked conditions. This strongly suggests that the processing of information under both tasks must be very similar. That is, if the $S$ can search faster than he can remember, or if he can do it in parallel, then search performance should be much better than memory. Further, this difference should be especially true under backward masking conditions, in which the time advantage would be accentuated. However, the differences between search and memory are small and parallel under both masked and degraded conditions. This suggests that apparently the $S$ must search through each item of the array, compare it to the critical one, and do this exhaustively even if he found the correct item on the first comparison. This follows closely the conclusion reached by Sternberg (1967) for measures of reaction time in search tasks. Apparently visual search is equivalent to memorizing in that each item had to be examined separately.

\section{REFERENCES}

AARONSON, D. Temporal factors in perception and short-term memory. Psychological Bulletin, 1967, 67, 130-144.

HABER, R. N. Temporal integration of supraliminal perceptual processes. Symposium Presentation, American Psychological Association Convention, San Francisco, 1968.

HABER, R. N. Information processing analyses of visual perception: An introduction. In R. N. Haber (Ed.), Information processing approaches to visual perception. New York: Holt, Rinehart, Winston, 1969, in press.

HABER, R. N., \& NATHANSON, L. S. Information processing time for recognition. Perception \& Psychophysics, in press.

LISS, P. L. The first 100 miliseconds of vision. Quarterly Progress Report, Research Laboratory of Electronics, MIT, July 15, 1967.

LISS, P. L. Does backward masking by visual noise stop visual analysis? Paper presented at Eastern Psychological Association Convention, Washington, D. C. April, 1968.

NEISSER, U. Cognitive psychology. New York: Appleton-CenturyCrofts, 1967.

SPERLING, G. A model for visual memory tasks. Human Factors, 1963, $5,19-31$.

SPERLING, G. Successive approximations to a model for short-term memory. Acta Psychologica, 1967, 27, 285-292.

STERNBERG, S. Two operations in character recognition: Some evidence from reaction time measures. Perception \& Psychophysics, $1967,2,45-53$.

\section{NOTE}

1. This research was partially supported by a grant from the United States Public Health Service, MH 10753, and a Grant from the National Science Foundation, GB 5910, both to the second author. 